\title{
Health Related Quality of Life (HRQOL) and its correlation with academic performance of medical students
}

\author{
Shahid Sarwar ${ }^{1}$, Abdul Aleem ${ }^{2}$, \\ Muhammad Arif Nadeem ${ }^{3}$
}

\begin{abstract}
Objective: To determine health related quality of life (HRQOL) of medical students and its correlation with their academic performance.

Methods: Cross sectional study at Services Institute of Medical Sciences, included students of $4^{\text {th }}$ and final year MBBS, who filled SF-36 proforma of HRQOL. Scores of 8-domains and of physical component and mental component summary were determined. Marks in all professional examinations were used to stratify students as high performers ( $\geq 70 \%$ marks) and average performing students ( $<70 \%)$. HRQOL scores was correlated with academic performance using unpaired student's $t$-test.

Results: Among 267 students included, mental health score $(56.2 \pm 21.3)$ was lower than physical health component score $(69.03 \pm 18.5)$. Role limitation due to emotional health (RE) (44.81), Vitality (VT) (54.19) and general health perception $(\mathrm{GH})(58.89)$ had lower scores among 8domains of questionnaire. Female students had significantly lower scores in role limitation due to emotional problems ( $p$ value $<0.04)$, vitality $(<0.05)$, bodily pain ( $\mathrm{p}$ value $<0.05$ ) and general health perception ( $\mathrm{p}$ value $<0.03$ ) than male students. Physical health and role limitation due to physical health domains were better in high performing students. Conclusion: Mental health of medical students is suboptimal, especially among female students. Students with better physical health have better academic performance.
\end{abstract}

KEYWORDS: Academic performance, Health related quality of life, Mental health, Physical health.

doi: https://doi.org/10.12669/pjms.35.1.147

How to cite this:

Sarwar S, Aleem A, Nadeem MA. Health Related Quality of Life (HRQOL) and its correlation with academic performance of medical students. Pak J Med Sci. 2019;35(1):-266-270. doi: https://doi.org/10.12669/pjms.35.1.147

This is an Open Access article distributed under the terms of the Creative Commons Attribution License (http://creativecommons.org/licenses/by/3.0), which permits unrestricted use, distribution, and reproduction in any medium, provided the original work is properly cited.

\section{INTRODUCTION}

1. Shahid Sarwar, MBBS, FCPS (Med)

FCPS (Gastroenterology) MCPS-HPE.

Associate Professor,

2. Abdul Aleem, MBBS.

Post-Graduate Resident Gastroenterology \& Hepatology,

3. Muhammad Arif Nadeem, MBBS, FCPS (Medicine).

Professor of Medicine,

1-3: Services Institute of Medical Sciences,

Lahore, Pakistan.

Correspondence:

Dr. Shahid Sarwar,

Associate Professor,

Services Institute of Medical Sciences,

Lahore, Pakistan.

E-mail: shahidsarwardr@gmail.com

* Received for Publication

* $1^{\text {st }}$ Revision Received:

* $2^{\text {nd }}$ Revision Received:

* Final Revision Accepted:
October 1, 2018

October 4, 2018

December 6, 2018

December 8, 2018
The term quality of life was first introduced in social sciences after Second World War. It was the consequence of realization that good life is more valuable than financial well-being which was always considered a bench mark for standard of living. ${ }^{1}$ The WHO defines Quality of Life as "an individual's perception of their position in life in the context of the culture and value systems in which they live and in relation to their goals, expectations, standards and concerns". ${ }^{2}$ It is a broad ranging concept affected in a complex way by the person's physical health, psychological state, personal beliefs, social relationships and their relationship to salient features of their environment. ${ }^{3}$ In other words quality of life is the outcome of individual's perceptions. Health related quality of life (HRQOL) represents the influence of health status, medical 
treatment and health policies on these perceptions of well-being. ${ }^{4}$

Medical students are a highly educated population group, who encounter multiple emotions during transformation from insecure student to young knowledgeable physician. ${ }^{5}$ During their five years stay in medical college and especially after introduction to clinical settings in senior years, they encounter loss of control, illnesses and helplessness while dealing with patients and their diseases, sometimes resulting in worsening depression and anxiety. It can lead to deteriorating mental health of students. Multiple factors can exaggerate this situation such as academic overload ${ }^{6}$, contact with diseases $^{7}$ and death and ever expanding medical curriculum. ${ }^{8}$ Anxiety, depression and worsening stress is on rise among medical students. ${ }^{9}$

Studies have identified a strong link between these factors responsible for poor health related quality of life and academic performance of students. ${ }^{10}$ Academic performance of a student reflects his learning. Being groomed to practice a sensitive profession like medicine, his personal and professional development for future practice is depicted in performance of examinations. Studies have shown that academic performance of a student can predict his professional competence later. ${ }^{11}$

Multiple factors can affect his academic performance like, learning environment, instructional strategies being adopted at institution, curricular overload and attitude of faculty. But does health related quality of life effect students learning is still far from being fully explored.

Objective of our study was to determine the health related quality of life of students of medical college and to correlate it with their academic performance.

\section{METHODS}

This cross-sectional study was conducted at Services Institute of Medical Sciences Lahore in August 2018. Approval was obtained from the institutional review board. Purposive nonprobability sampling was done. Students of $4^{\text {th }}$ year and final year, having at least four years of professional learning and been through multiple professional examinations were included in study. Informed consent was taken from the participants. Students not willing to participate and those with pending result of professional examination were excluded. Students filled the study proforma in a dedicated session of one hour.

Instrument used for evaluation of HRQOL was Short Form-36 (SF-36), a 36 item questionnaire developed in Medical Outcome Study (MOS) for measuring health related quality of life. ${ }^{12}$ It measures quality of life across eight domains, which are both physically and emotionally based. These domains are Physical Functioning (PF), role limitation due to physical health (RP), role limitation due to Emotional Problems (RE), Vitality (VT), General Mental Health (MH), Social Functioning (SF), bodily pain (BP) and General Health perception (GH). The SF36 has been widely validated for numerous professions and patient groups. ${ }^{13}$

Once filled, an aggregate percentage score is produced for each of eight domains measured by SF-36. It is done in two step process. Each of the question responses is related to a different pre-coded numeric value. The response to each question is translated into raw score from 0 to 100, with 0 representing a very low level quality of life (QoL) and 100 depicting a very positive response to the item. In second step, we took these translated item scores and determined the score for each of the eight domain by adding scores of items related to a domain and dividing it by number of items used. For domain of PF, we added scores of item no $3,4,5,6,7,8,9,10,11$ and 12 and divided it by 10 . Similarly we added scores of item $13,14,15$ and 16 and divide it by 4 to determine score of RP, scores of item 17,18,19 gave score of RE, item 23, 27, 29 and 31 gave score for VT, item 24, 25, 26, 28 and 30 calculated score for $\mathrm{MH}$, addition of item 20 and 32 and dividing by 2 produced score for SF, 21 and 22 items for BP and item 1, 33, 34, 35 and 36 gave score for GH. We also calculated Physical component Summary(PCS) depicting physical QoL by averaging scores of $\mathrm{PF}, \mathrm{RP}, \mathrm{BP}$ and $\mathrm{GH}$ and Mental Component Summary(MCS) representing mental QoL by determining average of SF, RE, MH and VT. We used criterion based interpretation of SF-36 to correlate it with academic performance of students.

Academic performance was determined by adding percentage marks of all professional examinations taken by students and dividing it by number of examinations. Students with percentage of $70 \%$ or above were classified as high performers while those with less than $70 \%$ percentage in aggregate of all professional examinations were labeled as average performers.

Statistical Analysis: Data was analyzed using SPSS ${ }^{\circledR}$ 20. Variable were expressed as mean \pm standard deviation (SD) or in percentage where appropriate for normally distributed variables while median and interquartile range (IQR) for variables not normally distributed. Shapiro-wilk test was 
used for checking whether variables were normally distributed or not. We determined Cronbach's alpha to determine internal consistency of SF-36 and value above 0.7 was considered satisfactory for study group.

Eight domains measured by SF-36, Physical ComponentSummary (PCS) and Mental Component Summary (MCS) were analyzed for association with academic performance using unpaired student's $t$ test for normally distributed variables while MannWhitney's test for non-parametric variables.

\section{RESULTS}

Total of 267 students participated in study, $184(68.9 \%)$ girls and $83(31.1 \%)$ boys. Student participation in survey was $91.3 \%(137 / 150)$ in final year and $86.6 \%(130 / 150)$ in $4^{\text {th }}$ year class. Data collected from SF-36 was checked for internal consistency by determining Cronbach's alpha, which was 0.918 , suggesting excellently consistent data. Apart from PF, data of other domains of quality of life was normally distributed. Scores of students were better in domains of PF (mean 82.94 $\pm 20.09)$ and BP (mean 73.73 \pm 34.6 ) while mean scores in RE (44.81), VT (54.19) and GH (58.89) were relatively on lower side. RF (60.58), $\mathrm{MH}$ (62.20) and SF (63.71) domains had average values. Mean score for physical component summary was $69.03( \pm 18.49)$ and for mental component summary it was 56.23 $( \pm 20.5)$ suggesting poor state of emotional health in our students.

Comparison of male and female students in scores across different domains of quality of life is shown in Table-I. Scores of Role limitation due to emotional problems (RE) (p value 0.04 ), Vitality (VT)
( $p$ value 0.05 ), bodily pains (BP) ( $p$ value 0.05 ) and general health perceptions $(\mathrm{GH})$ ( $p$ value 0.03 ) were significantly better in male students. Male students had better physical component summary (PCS) scores, $73.03( \pm 15.15)$ as compared to $67.23( \pm 18.8)$ in female students ( $p$ value 0.01 ). Mental component summary scores were not significantly different, $59.64( \pm 21.15)$ in male as compared to $54.69(21.35)$ in female students ( $\mathrm{p}$ value 0.08 ).

Students of $4^{\text {th }}$ year and final year were comparable in all domains of quality of life except general health $(\mathrm{GH})$ which was better for final year students, $62.29( \pm 18.97)$ vs $4^{\text {th }}$ year score of 55.30 $( \pm 19.61)(\mathrm{p}<0.003)$.

On reviewing academic performance only $38(14.2 \%)$ students had cumulative academic scores of $65 \%$ or less, scores were between $65 \%$ to $70 \%$ in $66(24.7 \%)$ students, $90(33.7 \%)$ students had scores between $70 \%$ to $75 \%$ and $73(27.3 \%)$ students had examination scores above $75 \%$. As per our bench mark for performance status, $162(60.7 \%)$ students were high performers with examination scores $\geq$ $70 \%$ while $105(39.3 \%)$ were average performing students.

In order to identify effect of different domains of quality of life on academic performance, we compared high performing and average performing students as shown in Table-II. High performing students had better scores in most of SF-36 domains but difference was statistically significant only in domains of Physical Functioning (PF) and role limitation due to physical health (RP), both better in high performing students, 85.03( \pm 17.12$)$ mean score in PF as compared to $79.71( \pm 23.6)$ in average per-

Table-I: Effect of Gender on domains of quality of life

\begin{tabular}{lccc}
\hline Domains of QOL & $\begin{array}{c}\text { Male students score } \\
(\text { Mean } \pm \text { SD) }\end{array}$ & $\begin{array}{c}\text { Female students score } \\
(\text { Mean } \pm \text { SD) }\end{array}$ & P value \\
\hline Physical functioning (PF) & $84.93(19.0)$ & $82.03(20.1)$ & 0.27 \\
Role limitation due to physical health (RP) & $66.86(37.06)$ & $57.74(39.52)$ & 0.07 \\
Role limitation due to emotional health (RE) & $52.61(43.5)$ & $41.3(42.35)$ & 0.04 \\
Energy/Fatigue (VT) & $57.46(18.2)$ & $52.7(18.9)$ & 0.05 \\
Emotional well-being (MH) & $65.1(20.1)$ & $60.8(20.1)$ & 0.11 \\
Social functioning (SF) & $63.4(24.5)$ & $63.8(24.05)$ & 0.88 \\
Pain (BP) & $77.74(22.7)$ & $71.92(22.5)$ & 0.05 \\
General health perception (GP) & $62.59(17.7)$ & $57.2(20.17)$ & 0.03 \\
Physical component summary & $73.03(15.1)$ & $67.23(18.8)$ & 0.01 \\
Mental component summary & $59.64(21.1)$ & $54.69(21.3)$ & 0.08 \\
\hline
\end{tabular}


Table-II: Domains of quality of life and academic performance.

\begin{tabular}{lccc}
\hline Domains of $Q O L$ & $\begin{array}{c}\text { High performers } \\
\text { mean } \pm S D\end{array}$ & $\begin{array}{c}\text { Average performers } \\
\text { mean } \pm S D\end{array}$ & P value \\
\hline Physical functioning PF & $85.03(17.12)$ & $79.71(23.6)$ & 0.03 \\
Role limitation due to physical health RP & $64.5(37.4)$ & $54.52(40.54)$ & 0.04 \\
Role limitation due to emotional problems RE & $46.5(43.06)$ & $42.2(42.9)$ & 0.42 \\
Energy/fatigue VT & $54.96(18.0)$ & $53(20.06)$ & 0.40 \\
Emotional well-being MH & $62.41(19.6)$ & $61.86(21)$ & 0.82 \\
Social functioning SF & $65.20(23.7)$ & $61.42(24.7)$ & 0.21 \\
Pain BP & $74.95(21.6)$ & $71.85(24.3)$ & 0.27 \\
General health perception GP & $58.14(18.9)$ & $60.04(20.4)$ & 0.43 \\
Physical component summary PCS & $70.65(17.7)$ & $66.53(19.4)$ & 0.07 \\
Mental component summary MCS & $57.27(21.2)$ & $54.62(21.6)$ & 0.32 \\
\hline
\end{tabular}

forming students ( $\mathrm{p}$ value 0.03 ) and $64.5( \pm 37.4)$ for high performers in RP as compared to $54.52( \pm 40.5)$ of average performing students ( $p$ value 0.04 ).

\section{DISCUSSION}

During last few decades, education has moved from behaviorism to constructivism due to understanding that instead of using examinations and grades to promote learning, focus should be on helping student in constructing his knowledge through self-directed learning. ${ }^{14}$ This transformation is further augmented by evolution of social learning theory which says that learning does not occur in isolation but is effected by learner's environment and his sense of well-being. ${ }^{15}$

Impact of quality of life on learning of student is now being given due importance. Paro HB, et al identified that quality of life of students worsens over time during their stay in institution as it was lower in students of $4^{\text {th }}, 5^{\text {th }}$ and $6^{\text {th }}$ year as compared to those in $1^{\text {st }}$ year of learning. ${ }^{16}$

We have observed lower scores in aspects of quality of life related to mental health as compared to physical component scores in our study. In a study of 165 medical students and 93 doctors, prevalence of depression was $28.6 \%$ and that of anxiety $28.7 \%{ }^{5}$ This impaired mental status may continue from student life to post-graduate training and may result in early burn-out in physician's practical life. Cecil J, et al in a study of behaviors leading to burn out in medical students noted that 55\% students report high level of emotional exhaustion, $34 \%$ experienced de-personalization and 46.6\% had low level of personal accomplishment. Factors responsible for mental impairment were lack of physical activity, year of study and female gender. ${ }^{17}$ Encouragement of healthier life style and promotion of extra-curricular activities can help in improving mental health of students.

This effect is more pronounced in female students. Backovic DV, et al concluded that female students suffer more stress and burnout especially during attending autopsy and interaction with patients in clinical training. ${ }^{18}$ Female participants of our study had poor scores in role limitation due to emotional problems, vitality, bodily pains, general health perception and physical component summary scores as compared to male students. It brings forth need to identify root cause of poor status of these domains in female students and taking measures for improvement to aid their learning.

We have identified significant association between physical health related quality of life and academic performance of students, though high performing students had higher scores in most mental health domains of HRQOL as well. In a study of 78 medical students of Sri Lanka, quality of life scores were lower before examination as compared to scores after examination. It is understandable that examination adds to mental and physical stress. In this study students with better quality of life had superior performance in examination as well. ${ }^{19}$ McIsaac JL, et al in a study of elementary school students concluded that students with unhealthy lifestyle behaviors were more likely to have poor academic performance. ${ }^{20}$ Studies have identified genetic markers to explain complex association of poor health with lower academic achievements. ${ }^{21}$ 
We have only included $4^{\text {th }}$ and final year medical students. Inclusion of students of $1^{\text {st }}$ to $3^{\text {rd }}$ year may have made our results more generalizable. Another limitation can be timing of data collection as we conducted this survey close to professional examination and quality of life score can vary in relation to proximity to examination. Despite these limitations, our study has enabled us to highlight issues related to quality of life of our students, an aspect still largely unexplored in our region. It also guides us to conduct further research for in-depth study aimed at identifying measures to improve quality of life of medical students as this will facilitate better academic performance and brilliance in professional career.

\section{CONCLUSION}

Mental health of medical students is suboptimal as compared to physical health especially among female students. Students with better physical health have better academic performance.

Source of funding: None.

Conflict of interest: None to declare.

\section{REFERENCES}

1. Mazaheri M. Overall and specific life satisfaction domains preliminary Iranian students norms. Iran J Pub Health. 2010;39(2):89-94.

2. WHOQOL: Measuring quality of life. Available at http://w ww.who.int/healthinfo/survey/whoqol-qualityoflife/en/

3. Meeberg GA. Quality of life: a concept analysis. J Adv Nurs. 1993;18(1):32-38. doi: 10.1046/j.1365-2648.1993.18010032.

4. Ebrahim S. Clinical and public health perspectives and applications of health-related quality of life measurement. Soc Sci Med. 1995;41(10):1383-1394. doi: 10.1016/02779536(95)00116-o.

5. Ahmad I, Banu H, Fageer R, Al-Suwaidi R. Cognitive emotions: Depression and anxiety in medical students and staff. J Crit Care. 2009;24(3):e1-7. doi: 10.1016/j. jcrc.2009.06.003.

6. Guthrie E, Black D, Bagalkote H, Shaw C, Cambell M, Creed F. Psychological stress and burnout in medical students: a five year prospective longitudinal study. J R Soc Med. 1998;91:237-243. doi: 10.1177/014107689809100502.

7. MacLeod RD, Parkin C, Pullon S, Robertson G. Early clinical exposure to people who are dying: learning to care at the end of life. Med Educ. 2003;37:51-58. doi: 10.1046/j.13652923.2003.01412.x.

8. Kiessling C, Schubert B, Scheffner D, Burger W. First year medical student's perceptions of stress and support: a comparison between reformed and traditional track curricula. Med Educ. 2004;38:504-509. doi: 10.1046/j.13652929.2004.01816.x.

9. Compton MT, Carrera J, Frank E. Stress and depressive symptoms/dysphoria among US medial students: Results from a large, nationally representative survey. J Nerv Ment Dis. 2008;196:891-897. doi: 10.1097/ nmd.0b013e3181924d03.
10. Drybye LN. Thomas MR, Massie FS, Power DV, Eacker A, Harper W, et al. Burnout and suicidal ideation among US medical students. Ann Intern Med. 2008;149:334-341. doi: 10.7326/0003-4819-149-5-200809020-00008.

11. Tartas M, Walkiewicz M, Majkowicz M, Budzinski W. Psychological factors determining success in a medical career: a 10-year longitudinal study. Med Teach. 2011;33(3):e163172 doi: 10.3109/0142159x.2011.544795.

12. McHorney CA, Ware JE, Raczek AE. The MOS 36-item Short-Form Health Survey (SF-36): II. Psychometric and clinical tests of validity in measuring physical and mental health constructs. Med Care. 1993;31(3):247-263. doi: 10.1097/00005650-199303000-

13. Salazar FR, Bernabe E. The Spanish SF-36 in Peru: factor structure, construct validity, and internal consistency. Asia Pac J Public Health. 2015;27(2):NP2372-2380. doi: $10.1177 / 1010539511432879$.

14. Ertmer PA, Newby TJ. Behaviorism, Cognitivism, Constructivism: Comparing Critical Features from an Instructional Design Perspective. Performance Improvement Quarterly. 1993;6(4)pp:50-72. Available at http://vcs.ccc. cccd.edu/crs/special/ertnew1.htm

15. Bandura, Albert. Social Learning Theory. Stanford University, 1971. Available at: http://www.esludwig. com/uploads/2/6/1/0/26105457/ bandura sociallearningtheory.pdf

16. Paro $\mathrm{HB}$, Morales NM, Silva $\mathrm{CH}$, Rezende $\mathrm{CH}$, Pinto $\mathrm{RM}$, Morales RR, et al. Health-related quality of life of medical students. Med Educ. 2010;44(3):227-235. doi: 10.1111/j.13652923.2009.03587.x.

17. Cecil J, McHale C, Hart J, Laidlaw A. Behavior and burnout in medical students. Med Educ Online. 2014;19:25209. doi: 10.3402/mep.v19.25209.

18. Backovic DV, Zivojinovic JI, Maksimovic J, Maksimovic M. Gender differences in academic stress and burnout among medical students in final years of education. Psychiatr Danub. 2012;24(2):175-181.

19. Hettiarachchi M, Fonseka CL, Gunasekara P, Jayasinghe $\mathrm{P}$, Maduranga D. How does the quality of life and the underlying biochemical indicators correlate with the performance in academic examinations in a group of medical students of Sri Lanka? Med Educ Online. 2014;19:1. doi:10.3402/meo.v19.22772

20. McIsaac JL, Kirk SFL, Kuhle S. The association between health behaviours and academic performance in Canadian elementary school students: a cross-sectional study. Int J Environ Res Public Health. 2015;12:14857-14871. doi: 10.3390/ijerph121114857.

21. Ding W, Lehrer SF, Rosenquist JN, Audrain-McGovern J. The impact of poor health on academic performance: new evidence using genetic markers. J Health Econ. 2009;28(3):578-597. doi: 10.1016/j.jhealeco.2008.11.006.

\section{Author's contribution:}

SS conceived, designed, did statistical analysis and manuscript writing.

SS and AA did data collection and manuscript review.

MAN did manuscript review and final approval. 